\title{
Gebelik ve emzirme döneminde kozmesötik kullanımı
}

\section{Use of cosmeceuticals during pregnancy and lactation period}

\author{
Hamza Yıldız, Özlem Karabudak Abuaf*
}

Eskișehir Asker Hastanesi, Deri ve Zührevi Hastalıklar Kliniği, Eskișehir, Türkiye *Gülhane Askeri Tıp Akademisi Haydarpașa Eğitim Hastanesi, Deri ve Zührevi Hastalıklar Kliniği (Emekli Öğretim Üyesi), İstanbul, Türkiye

\section{Özet}

Son yıllarda gebelik ve emzirme döneminde gerek bitki gerekse bitki ekstrelerinin (kozmesötik) topikal ya da sistemik kullanımı giderek yaygınlaşmaya başlamıştır. Kullanıcılar bitki ve bitki ekstrelerinin sadece faydalı olduğuna değil aynı zamanda güvenli olduğuna inanırlar. Binlerce bitki ve bitki ekstresinin çok az bir kısmı bilimsel olarak incelenmiştir. Bu derlemenin amacı gebelik ve laktasyon döneminde kullanılan bazı dermato-kozmesötiklerin güvenliği hakkında bilgi vermektir. (Türkderm 2013; 47: 194-9)

Anahtar Kelimeler: Gebelik, kozmesötik

\section{Summary}

Use of topical or systemic herbs and herbal extracts (cosmeceuticals) during pregnancy and lactation period has increased in the recent years. These cosmeceuticals are not only viewed as having clinical benefits but are also generally believed to be safe by users. A small part of thousands of plants and botanical ingredients has been investigated scientifically. The purpose of this review was to provide the safety information about the dermatologic cosmeceuticals which can be used during pregnancy and lactation period. (Turkderm 2013; 47: 194-9)

Key Words: Pregnancy, cosmeceutical

\section{Giriş}

Tarihsel olarak gebeler, hem gebeliğe bağı rahatsızlıkların tedavisinde hem de kendi sağlıkları ve bakımları için topikal veya sistemik kozmesötikler kullanmıştır1,2.Dünyada son yıllarda hem tamamlayıcı hem de alternatif tıbba olan yoğun ilgi doğrultusunda özellikle bitki ve bitki ekstrelerinin oral ya da topikal formlarının kullanımı belirgin düzeyde artmıştır ${ }^{3}$.

\section{Tanımlar}

Gıda takviyesi, kozmetik ürünlerin ve kozmesötik tanımlarının iyi anlaşılması gerekir. Vitamin, mineral, amino asit, bitki ve bitki ekstreleri içeren maddelerin tamamı FDA (Food and Drug Administration/Gıda ve İlaç Dairesi) tarafından gıda takviyesi (dietary supplements) olarak nitelendirilmektedir4. FDA'in kozmetik ürün tanımı; “Dökülmek, serpilmek, ovulmak veya başka herhangi bir şekilde uygulanmak suretiyle vücudun veya vücudun herhangi bir kısmının temizlenmesi, güzelleştirilmesi, cazibesinin arttırıması veya görünüşünün değiştirilmesi amacı ile uygulanan preparatlar ve bunların hazırlanması için kullanılan maddelerdir." şeklindedir. Genel olarak kozmetik ürünler deri ve eklerini temizlemek ya da güzelleştirmek amacıyla kullanılırken; bitki ve bitki ekstreleri içeren kozmesötik maddelerde hedef, fizyolojik süreçlere etki ederek fonksiyonları değiştirmektir5. 
Hem dünyada hem de ülkemizde son yıllarda gerek tamamlayıcı gerekse de alternatif tıbba olan yoğun ilgi doğrultusunda özellikle bitki ve bitki ekstrelerinin (kozmesötikler) oral ya da topikal formlarının kullanımı belirgin düzeyde artmıştır ${ }^{3}$. Eisenberg ve ark. yaptıkları bir çalışmada ABD'de kozmesötik kullanımında 1990 yılından 1997 yılına kadar \%500 artış olduğunu saptamıştır6.

Gebelik ve emzirme döneminde kadınların bir kısmı akne vulgaris, stria gravidarum, kloazma, postpartum telogen effluvium, hirsutizm, palmar eritem, kserozis gibi gerek gebeliğe özgü gerekse gebeliğe özgü olmayan çeşitli dermatozların giderilmesinde aynı zamanda bakımlı ya da daha sağlıklı görünebilmek amacıyla da kozmesötik kullanmaktadır ${ }^{1}$. Nordeng ve ark. tarafından hamilelik döneminde kozmesötik kullanımına dair yapılan bir araştırmada gebelerin \%36'sının gebelik boyunca ortalama 1,7 kozmesötik ürünü kullandığını ortaya koymaktadır. Yine aynı araştırmada bu kadınların \%43'ünün emzirme döneminde özellikle sütlerini arttırmak amacıyla çeşitli bitki ve bitki ekstresi kullandığı saptanmıştır. Gebelik ve emzirme döneminde kadınlar "güvenli" olduğunu düşündükleri için kozmesötik ürünleri daha rahat ve yaygın kullanmaktadırlar. Kozmesötiklerin genellikle aile ve arkadaş tavsiyesi ile kullanıldığı ve kozmesötiklerin güvenliği hakkında bilgi sahibi olunmadığı saptanmıştır?.

Birçok bitki ve bitki özü 'folklorik tıp' olarak tanımlayabileceğimiz deneme yanılma şeklinde tarih boyunca süregelen kullanımı nedeniyle uzun bir geçmişe sahip olmalarına karşın, çoğunun bilimsel olarak gözden geçirilmesi ve değerlendirilmesi oldukça yakın zamanda başlamış ve henüz tam olarak araştırılmamıştır. Üstelik doğada var olan bu etken maddelerin kimyasal formüllerde dayanıklılık, koku, kimyasal geçimsizlik ve standardize etmek gibi aşılması gereken birçok farklı problemleri de vardır ${ }^{8}$.

Bitki ve bitki ekstreleri hakkında bilgi sağlayan resmi kurumlar: Kozmesötikler hakkında detaylı bilgi için başvuruda ilk akla gelen kurum FDA'dir. Fakat kozmesötikler tanımlama olarak halen ilaç statüsünde kabul edilmemeleri nedeniyle $A B D$ de dahil olmak üzere birçok ülkede kontrol, test ya da onaya gerek olmadan üstüne içeriğinin yazılması koşuluyla üretilir ve reçetesiz satılabilirler ${ }^{1}$.

Almanya'da bitkisel ürünlerle ilgilenen 'Alman E Komisyonu' denilen düzenleyici bir komisyon bulunmaktadır. 1978 yılında Alman hükümeti tarafından kurulmuştur. Bu komisyon bitkiler üzerinde yapılmış olan çalışmaları inceleyerek kanıt seviyesine göre güvenlik ve etkinlik profillerini değerlendirmektedir. Bu komisyonun yayımladığı monograflarda toplam 380 tane kozmesötiğin onaylandığı ya da onaylanmadığı, kozmesötiklerin kullanımı, endikasyonu, yan etkileri, diğer ilaçlarla ya da kozmesötiklerle etkileşimi, gebelik ve laktasyonda kullanımı gibi birçok bilgiler bulunmaktadır ${ }^{9}$.

Diğer önemli bir kaynak ise EMEA (European Medicines Agency/ Avrupa İlaç Dairesi)'nin hazırladığı monograflardır. Bitkiler üzerinde yapılmış olan bilimsel çalışmaları inceleyerek kanıt seviyesine göre güvenlik ve etkinlik profillerini değerlendirmektedir. Bu monografilerde E komisyonundaki gibi kozmesötiğin onaylandığı veya onaylanmadığı, kozmösotiklerin kullanımı, endikasyonu, yan etkileri, diğer ilaçlarla ve kozmesötiklerle etkileşimi, gebelik ve laktasyonda kullanımı gibi birçok bilgiler bulunmaktadır ${ }^{10}$.
FDA gıda takviyelerinin içerisinde değerlendirdiği kozmesötiklerin güvenliğini takip etmektedir. Kozmesötik üreticilerinin, kozmesötiğe bağlı olarak oluşan zarar verici etkiler meydana geldikten sonra bu durumu FDA'ya bildirmeleri zorunludur. Bu ürünler incelenip gerekli görüldüğü takdirde yasaklanabilmektedir. Eylül 2010 ile Mart 2011 arasında ayda ortalama 120 yan etki bildirilmiştir. Günden güne bu sayı artmaktadır. 2009 yılında Amerika Zehirlenme Kontrol Merkezi'ne gida takviyesinden kaynaklanan 29.000'den fazla arama gelmiştir. Bunlarında 3000'den fazlasına tıbbi tedavi uygulandığı rapor edilmiştir. Bir hastanın ise öldüğü bildirilmiştir. Beklenmedik yan etki, hastalık ve ilaç etkileşimi olan birçok hastanın da bu merkezi veya üretici firmayı aramadığı dikkate alınmalıdır ${ }^{11}$. Kozmosötikler hakkında gerek hastalarımızın gerekse sağlık çalışanların yeteri kadar bilgi sahibi olmadığı görülmektedir. Bu konuda sağlık çalışanlarının ve hastaların yeterince bilgilendirilmesi gerekmektedir.

Kozmesötikler hakkında yanlış bilinen efsaneler;

- "Doğal olan güvenlidir ve doğal olan daha iyidir." Unutulmamalıdır ki zehirli mantar da doğal bir bitkidir fakat insanları öldürebilir. Bunun gibi doğada, alındığında insanlarda birçok yan etki, alerji ve hatta ölüme neden olabilen zararlı bitki bulunmaktadır12,13.

- "Yüzlerce yıldır kullanılıyor, dolayısıyla iyi olmalı". Yüzlerce yıldır kullanılmaktadırlar, fakat güvenlikleri konusunda bilimsel kanıt bulunmamaktadır12,13

- "Eğer bitki ve bitki ekstreleri üreten firmaların iddiaları doğru olmasa FDA, Sağlık Bakanlıkları bunları iddia etmelerine izin vermezdi. Eğer zararlı olsalardı, satılmalarına izin verilmezdi". Kozmesötikler tanımlama olarak halen ilaç statüsünde kabul edilmemeleri nedeniyle FDA gibi güçlü bir kurumun olduğu $A B D$ de dahil birçok ülkede kontrol, test ya da onaya gerek olmadan üstüne içeriğinin yazılması koşuluyla üretilir ve reçetesiz satılabilirler. Bu ürünler FDA tarafından ancak zarar verdiğinde güvensiz olarak ilan edilmektedir8,12

- "Düzenli kullanılan ilaçlarla bitki ve bitki ekstrelerini birlikte almak zararsızdır". Birçok insan reçete edilmiş ve hali hazırda kullandığı ilaçlarla bitki ve bitki ekstrelerin birlikte kullanmanın zararsız olacağını düşünmektedir. Bu tamamen yanlış bilgidir. Bitki ve bitki ekstreleri kullandığınız ilacın emilimini artırabilir veya azaltabilir. Bu da kullandığı ilacın kan konsantrasyonunu değiştirebiliri2.

Gebelik ve emzirme döneminde kullanılması yasaklanan birçok bitki ve bitki ekstresi (Blue Cohosh, Hellobore, Hemlock, Tragacanth vs.) bulunmaktadır12,14. Bu derlemede sadece dermatolojik amaçlı kullanılanlara yer verilmiştir. Iki temel başlık altında incelenecektir: Birincisi gebelikte sık görülen fizyolojik değişikliklerde kullanılan kozmesötiklerdir. íkincisi ise; gebelik ve emzirme döneminde oldukça sık olarak kullanılan dermatolojik anlamda ön plana çıkan bitki ve bitki ekstreleridir. Bu grup Tablo 1'de incelenmiştir. Bu tablo oluşturulurken, EMEA kozmesötik monografları dikkate alınmıştır. Monograf, tek bir konu üzerinde hazırlanmış yazıdır. Bitki monografları genellikle kozmosötiğin isimlendirilmesi, bileşenleri, uygulama aralığı, kontrendikasyonları, yan etkileri, diğer ilaçlarla uyumsuzluğu gibi bilgileri içerir.

Gebelik sırasında gebelerde meydana gelen hormonal, immünolojik, metabolik ve vasküler değişiklikler nedeniyle deride birçok fizyolojik değişiklikler ve gebeliğe özgün dermatozlar (pemfigoid gestasyones, 
gebeliğin intrahepatik kolestazı, gebeliğin ürtikeryal papül ve plakları, impetigo herpetiformis, gebeliğin lineer IgM dermatozu, prurigo gestasyones) görülmektedir15. Gebelikte sık görülen fizyolojik değişikliklerde kullanılan kozmesötikler ve güvenlikleri aşağıda derlenmiştir:

\section{Kloasma}

Vitis Vinifera (Grape Seed/Üzüm Çekirdeği) Ekstresi: 2004 yılında, 12 kloasmalı kadın hasta üzerinde yapılan bir kohort çalışmada, grape seed ekstresinden elde edilen oldukça kuvvetli bir anti-oksidan olan "proanthocyanidin"den zengin grape seed ekstresi 12 ay boyunca sistemik olarak kullanılmış. Etkinliğin 6 aylık oral tedavi sonunda pik yaptığı $(\% 83, p<0,01)$ saptanmış. Kloasmalı hastaların tedavisinde grape seed'in etkili ve güvenli olduğu öne sürülmüş16.

Pinus Pinaster (French Maritime Pine Bark extract/Fransız Deniz Çam Ağacı/Pycnogenol $\left.{ }^{\circledR}\right)$ Ekstresi: Vitamin $C$ ve E'den daha potent bir anti-oksidan olan "pycnogenol" aynı zamanda UV ışınlarına karşı koruyucu etkiye sahiptir. Pycnogenol pine bark ekstresinden elde edilmektedir. Pycnogenol, 2002 yılında yapılan bir çalışmada 30 kloasmalı hastaya, otuz gün boyunca 3 eşit bölünmüş dozda 75 mg/ gün "pycnogenol" oral olarak kullanılmış. Genel etkinlik oranının \%80 olduğu saptanmış. Herhangi bir yan etki tespit edilmemiş̧17.

\section{Stiria gravidarum}

Gebelik döneminde kadınların çoğunda (\%50-80) stria gravidarum geliştiği bildirilmektedir. Gebelerde stria gelişimini engellediği iddia edilen birçok ürün bu amaçla kullanılmaktadır. Birçok plasebo kontrollü çalışmada kullanılan ürünlerin etkili olmadığı vurgulanmaktadır ${ }^{18-21}$. Centella Asiatica (Gotu Kola) Ekstresi: Mallol ve ark. yaptığı çift kör klinik çalışmada, 40 kişilik plesebo grubunun (22) \%56'sında, 40 kişilik tedavi grubunun (14) \%34'ünde stria geliştiği saptanmış $(p<0,05)^{22}$.

Cocoa Butter (Kakoa Yağı): 2008 yılında yapılan, çok merkezli, çift kör, plasebo kontrollü, klinik çalışmada 91 hastaya cocoa butter, 84 hastaya plasebo uygulanmış. iki grup arasında istatistiksel olarak anlamlı bir fark gözlenmemiş ( $p=0,730) .2010$ yılında Buchanan ve arkadaşlarının 300 gebe üzerinde yaptığı araştırmada da gruplar arasında fark gözlenmemiş20.

Olive oil (Zeytin Yağı): Simin ve ark. yaptığı plasebo kontrollü çalışmada gruplar arasında bir fark olmadığı saptanmış ${ }^{19}$. Diğer bir randomize kontrollü çalışmada ise 50 hastaya plasebo 50 hastaya ise olive oil topikal olarak günde 2 kez 1 cc olarak uygulanmış ve gruplar arasında fark izlenmemiş23.

\section{Akne vulgaris}

Çok sayıda bitki ve bitki ektresi, akne vulgaris tedavisinde antiinflamatuvar, anti-hidrotik ve/veya antibakteriyel etkilerinden dolay kullanılmaktadır.

Melaleuca Alternifolia (Tea Tree Oil/Çay Ağacı Yağı): Avusturalya'ya özgü Melaleuca alternifolia isimli yerel bir ağacın yapraklarından elde edilmektedir. Güçlü anti-mikrobiyal ve antiinflamatuvar etkili olduğu saptanmıştır. Bu etkileriyle akne vulgariste etkili olduğu öne sürülmektedir24. Yüz yirmi dört hasta üzerinde yapılan randomize klinik çalışmada, \%5'lik benzoyl peroxide ile \%5'lik tea tree oil'in karşılaştırılığı bir çalışmada her ikisinin de istatiksel olarak etkili olduğu fakat "tea tree oil"in daha yavaş etkili olduğu saptanmıştır25. Randomize çift kör plasebo kontrollü bir klinik çalışmada ise topikal olarak $\% 5^{\prime}$ lik tea tree oil'in akne vulgaris tedavisinde etkili olduğu saptanmıştır26

Taninler (Tannins): Doğada tannins içeren çok sayıda bitki bulunmaktadır. Bunlara örnek olarak English walnut leaf (Juglans regia), Goldenrod (Salido virgaurea), Labrador tea (Ledun latifolium), Lavender (Lavandula angustifolia), White oak bark (Quercus alba), Agrimony (Agrimonia eupatoria) sayılabilir. Doğal astrenjan etkisinden dolayı akne vulgaris tedavisinde topikal olarak kullanılmaktadır26,27. 5-10 gram Hamamelis virginiana 0,24 litre suda kaynatılarak elde edilen ürün kullanılmaktadır ${ }^{1}$.

Vitex Agnus Castus (Chasteberry/Hayıt Meyvesi) Ekstresi: Chaste ağacından elde edilen vitex agnus castus yaygın olarak premenstrüel sendrom tedavisinde kullanılmaktadır. Sistemik olarak premenstrüel aknede kullanıldığında dopaminerjik mekanizmalarla etkili olduğu saptanmıştır. Komisyon E premenstrüel aknede 40 mg/gün olarak kullanılmasını önermektedir. Sistemik olarak gebelik ve emzirme döneminde kullanılması önerilmemektedir. Komisyon E vitex'in topikal olarak akne vulgaris tedavisinde kullanılmasına izin vermektedir27. Yukarıda sıralanmış olan bitki ve bitki ekstreleri hakkında Avrupa ilaç Dairesi'nce yayınlanmış monograf bulunmamaktadır.

Tablo 1'de görüldüğü gibi dermato-kozmesötiklerin gebelik ve laktasyon döneminde kullanımı ile ilgili yeterli bilimsel veri bulunmamaktadır. Topikal olarak kullanılan dermato-kozmesötiklerin deriden penetre olarak sistemik dolaşıma geçmeleri söz konusudur. Gerek topikal gerekse sistemik kozmesötik uygulamaları hakkında yeterli bilimsel araştırma mevcut değildir. EMEA, FDA ve Komisyon E bu kozmesötiklerin özellikle gebelik ve süt verme dönemindeki kadınlarda riskli olabileceğini belirtmekte ve kullanılmasını önermemektedir. Kullanmaya karar veren kadınların ise mutlaka doktorlarına danışmalarını önermektedir.

\section{Sonuç}

Bitkilerden elde edilen ürünlerin gerek oral gerekse topikal kullanımının son 10-15 sene içerisinde belirgin olarak artmış olmasına karşın, günümüzde halen bilimsel açıdan çok yoğun çalışma gerektiren bir alan olarak dikkatleri üzerine çekmektedir. Bitkilerden elde edilmiş olan ürünlerin etkinliği kadar güvenilir olmalarına, etki mekanizmalarının aydınlatımasına, formülasyonda stabilitelerine, formülasyon türlerine ve teknolojilerine ait çalışmalara, toksik etki, yan etki, çapraz reaksiyonlar gibi güvenlik profillerinin belirlenmesine intiyaç vardır. FDA, Komisyon E ve EMEA kozmesötiklerin gebelik ve laktasyon döneminde kullanımı ile ilgili yeterli bilimsel veriler olmadığ için kullanılmasını önermemektedir. 
Tablo 1. Gebelik ve emzirme döneminde oldukça sık olarak kullanılan dermatolojlk anlamda ön planda olan bitki ve bitki ekstreleri

\begin{tabular}{|c|c|c|c|}
\hline Kozmesötik & Dermatolojide kullanımı & Avrupa Illaç Dairesi10 & Diğer \\
\hline $\begin{array}{l}\text { Ginko (Gingko Biloba/Japon } \\
\text { Eriği Ekstresi) }\end{array}$ & $\begin{array}{l}\text { Sistemik: Vitiligo } \\
\text { Topikal: Nemlendirici }{ }^{34}\end{array}$ & Henüz monograf yayınlanmamış. & $\begin{array}{l}\text { Gebelikte kullanımından } \\
\text { kaçınılmalı }^{7}\end{array}$ \\
\hline $\begin{array}{l}\text { Panax ginseng (Ginseng/ } \\
\text { Beşparmak Kökü) }\end{array}$ & $\begin{array}{l}\text { Topikal: Atopik dermatit }{ }^{35} \text {, deri } \\
\text { kırışıklığ|36 }\end{array}$ & $\begin{array}{l}\text { Hamilelik ve emzirme döneminde güvenliği } \\
\text { kanıtlanmamıştı. Yeterli veri yokluğu } \\
\text { nedeniyle kullanılması tavsiye edilmez. }\end{array}$ & \\
\hline Soya ve İzoflavonlar & $\begin{array}{l}\text { Topikal: Deri elastikiyetini ve neminin } \\
\text { artırmak, yağlanmayı kontrol altına } \\
\text { almak, hiperpigmentasyon, kıl çıkışııı } \\
\text { azaltmak } 2,29,30,40\end{array}$ & Henüz monograf yayınlanmamış. & \\
\hline $\begin{array}{l}\text { Vitis Vinifera (Grape Seed/Üzüm } \\
\text { çekirdeği) }\end{array}$ & $\begin{array}{l}\text { Topikal: Antioksidan, antikarsinojenik, } \\
\text { antiinflamatuvar, antihistaminik }{ }^{2}\end{array}$ & $\begin{array}{l}\text { Hamilelik ve emzirme döneminde güvenliği } \\
\text { kanıtlanmamıştır. Yeterli veri yokluğu } \\
\text { nedeniyle kullanılması tavsiye edilmez. }\end{array}$ & \\
\hline $\begin{array}{l}\text { Matricia Alternifolia (Tea Tree/ } \\
\text { Çay Ağacı) }\end{array}$ & Topikal: Antiseptik, antibiyotik 29,30 & Henüz monograf yayınlanmamış. & \\
\hline $\begin{array}{l}\text { Camelia Sinensis (Black, Green, } \\
\text { Oolong, White Teas/Siyah, Yeşil, } \\
\text { Oolong ve Beyaz Çay) }\end{array}$ & $\begin{array}{l}\text { Topikal: Antioksidan, } \\
\text { fotoyaşlanma }\end{array}$ & Henüz monograf yayınlanmamış. & \\
\hline $\begin{array}{l}\text { Oenothera Biennis (Evening } \\
\text { Primrose/ } \\
\text { Çuha Çiçeği) }\end{array}$ & $\begin{array}{l}\text { Topikal: Atopik dermatit }{ }^{44,45} \\
\text { Sistemik: Reynoud fenomeni }{ }^{46} \\
\text { skleroderma }{ }^{47}\end{array}$ & $\begin{array}{l}\text { Hamilelik ve emzirme döneminde güvenliği } \\
\text { kanıtlanmamıştır. Yeterli veri yokluğu } \\
\text { nedeniyle kullanılması tavsiye edilmez. }\end{array}$ & $\begin{array}{l}\text { Gebelik } \\
\text { komplikasyonlarını } \\
\text { (membran rüptürü } \\
\text { vs.) arttırdığı için } \\
\text { gebelikte kullanımından } \\
\text { kaçınıımalı. }{ }^{48}\end{array}$ \\
\hline $\begin{array}{l}\text { Tanacetum Parthenium } \\
\text { (Feverfew/ } \\
\text { Gümüş Düğme) }\end{array}$ & Topikal: UV kaynaklı deri kanserleri²,30 & $\begin{array}{l}\text { Hamilelik ve emzirme döneminde güvenliği } \\
\text { kanıtlanmamıştır. Yeterli veri yokluğu } \\
\text { nedeniyle kullanılması tavsiye edilmez. }\end{array}$ & \\
\hline
\end{tabular}


Tablo 1. Devamı

\begin{tabular}{|c|c|c|c|}
\hline $\begin{array}{l}\text { Rosmarinus Officinalis } \\
\text { (Rosemary/ } \\
\text { Biberiye) }\end{array}$ & $\begin{array}{l}\text { Topikal: Eritem, deri tümörü } \\
\text { gelişiminin engellenmesij }{ }^{30,49}\end{array}$ & $\begin{array}{l}\text { Hamilelik ve emzirme döneminde güvenliği } \\
\text { kanıtlanmamıştır. Yeterli veri yokluğu } \\
\text { nedeniyle kullanılması tavsiye edilmez. }\end{array}$ & \\
\hline $\begin{array}{l}\text { Glycyrrhiza Glabra (Lıcorıce/ } \\
\text { Meyan) }\end{array}$ & $\begin{array}{l}\text { Topikal: Atopik dermatit }{ }^{50} \text {, akne } \\
\text { rozasea }^{30} \text {, deri kanserleri } \\
\text { Sistemik: Oral liken planus }\end{array}$ & $\begin{array}{l}\text { Hamilelik ve emzirme döneminde güvenliği } \\
\text { kanıtlanmamıştır. Yeterli veri yokluğu nede- } \\
\text { niyle kullanılması tavsiye edilmez. }\end{array}$ & $\begin{array}{l}\text { Erken doğum }{ }^{52} \text {, uterus } \\
\text { stimülasyonu }^{53}\end{array}$ \\
\hline $\begin{array}{l}\text { Aesculus Hippocastanum (Horse } \\
\text { Chestnut/ } \\
\text { At Kestanesi) }\end{array}$ & Topikal: Kırışıklık ${ }^{50}$, hematom ${ }^{54}$ & $\begin{array}{l}\text { Hamilelik ve emzirme döneminde güvenliği } \\
\text { kanıtlanmamıştır. Yeterli veri yokluğu nede- } \\
\text { niyle kullanııması tavsiye edilmez. }\end{array}$ & \\
\hline Avena Sativa (Oat/Yulaf) & $\begin{array}{l}\text { Topikal: Derinin inflamatuvar } \\
\text { hastalıklarında, kserozis, seboreik } \\
\text { dermatit, UVA blokajı, }{ }^{2,30}\end{array}$ & $\begin{array}{l}\text { Hamilelik ve emzirme döneminde güvenliği } \\
\text { kanıtlanmamıştır. Yeterli veri yokluğu nede- } \\
\text { niyle kullanılması tavsiye edilmez. }\end{array}$ & \\
\hline Coffee Arabica (Coffee/Kahve) & Topikal: Mukozit ${ }^{9}$, kırışıklık2,30 & Henüz monograf yayınlanmamış. & Spontan abortus ${ }^{55}$ \\
\hline
\end{tabular}

\section{Kaynaklar}

1. Bedi MK, Shenefelt PD: Herbal therapy in dermatology. Arch Dermatol 2002;138:232-42.

2. Draelos ZD: Cosmetic Dermatology: Products and Procedures. 1st ed Singapure: Black Well Publishing; 2010.

3. Goldback-Wood S DA, Lie LG, et al: Complementary medicine is booming worldwide. BMJ 1996:313:131-3.

4. http://www.fda.gov/forconsumers/consumerupdates/ucm050803.htm. 28 Nisan 2013.

5. Morganti P, Paglialunga S: EU borderline cosmetic products review of current regulatory status. Clin Dermatol 2008;26:392-7.

6. Eisenberg DM, Davis RB, Ettner SL, Appel S, Wilkey S, et al: Trends in alternative medicine use in the United States, 1990-1997: results of a followup national survey. JAMA 1998;280:1569-75.

7. Nordeng $\mathrm{H}$, Havnen GC: Use of herbal drugs in pregnancy: a survey among 400 Norwegian women. Pharmacoepidemiol Drug Saf 2004;13:371-80.

8. Karabudak Ö, Yıldız H: Kozmesötikler: Bitkiler ve Bitkisel Ekstreler. Turkiye Klinikleri J Cosm Dermatol-Special Topics 2012;5:46-53.

9. Blumenthal M, Busse WR, Goldberg A, et al: The Complete German Commission E Monographs. Therapeutic Guide to Herbal Medicines. Boston: American Botanical Council; 1998.

10. Herbal medicines for human use. European Medicines Agency; 2013. http:// www.ema.europa.eu/ema/index. 2013;28.

11. Bronstein AC, Spyker DA, Cantilena LR Jr, Green JL, Rumack BH, et al: 2010 Annual Report of the American Association of Poison Control Centers' National Poison Data System (NPDS): 28th Annual Report. Clinical toxicology Clin Toxicol (Phila) 2011;49:910-41.

12. Friedman JM: Teratology society: presentation to the FDA public meeting on safety issues associated with the use of dietary supplements during pregnancy. Teratology 2000;62:134-7.

13. Wal P, Wal A, Gupta S, Sharma G, Rai A: Pharmacovigilance of herbal products in India. J Young Pharm 2011;3:256-8.

14. Wright IM: Neonatal effects of maternal consumption of blue cohosh. J Pediatr 1999:134:384-5.

15. Beard MP, Millington GW: Recent developments in the specific dermatoses of pregnancy. Clin Exp Dermatol 2012;37:1-4

16. Yamakoshi J, Sano A, Tokutake S, et al: Oral intake of proanthocyanidin-rich extract from grape seeds improves chloasma. Phytother Res 2004;18:895-9.
17. Ni Z, Mu Y, Gulati O: Treatment of melasma with Pycnogenol. Phytother Res 2002:16:567-71.

18. Young $G L$, Jewell $D$ : Creams for preventing stretch marks in pregnancy. Cochrane Database Syst Rev 2000:CD000066.

19. Taavoni S, Soltanipour F, Haghani H, Ansarian H, Kheirkhah M: Effects of olive oil on striae gravidarum in the second trimester of pregnancy. Complement Ther Clin Pract 2011;17:167-9.

20. Buchanan K, Fletcher HM, Reid M: Prevention of striae gravidarum with cocoa butter cream. Int Journal Gynaecol Obstet 2010;108:65-8.

21. Moore J, Kelsberg G, Safranek S: Clinical Inquiry: Do any topical agents help prevent or reduce stretch marks? J Fam Pract 2012;61:757-8.

22. Mallol J, Belda MA, Costa D, Noval A, Sola M: Prophylaxis of Striae gravidarum with a topical formulation. A double blind trial. Int J Cosmet Sci 1991:13:51-7.

23. Soltanipoor F, Delaram M, Taavoni S, Haghani H: The effect of olive oil on prevention of striae gravidarum: a randomized controlled clinical trial. Complement Ther Med 2012;20:263-6.

24. Pazyar N, Yaghoobi R, Bagherani N, Kazerouni A: A review of applications of tea tree oil in dermatology. IntJ Dermatol 2013;52:784-90

25. Bassett IB, Pannowitz DL, Barnetson RS: A comparative study of tea-tree oil versus benzoylperoxide in the treatment of acne. Med J Aust 1990;153:455-8.

26. Enshaieh S, Jooya A, Siadat AH, Iraji F: The efficacy of $5 \%$ topical tea tree oil gel in mild to moderate acne vulgaris: a randomized, double-blind placebocontrolled study. Indian J Dermatol Venereol Leprol 2007;73:22-5.

27. Reuter J, Merfort I, Schempp CM: Botanicals in dermatology: an evidencebased review. Am J Clin Dermatol 2010;11:247-67.

28. Charles V, Charles SX: The use and efficacy of Azadirachta indica ADR ('Neem') and Curcuma longa ('Turmeric') in scabies. A pilot study. Trop Geogr Med 1992:44:178-81.

29. Thornfeldt C: Cosmeceuticals containing herbs: fact, fiction, and future Dermatol Surg 2005;31:873-80.

30. Baumann LS: Less-known botanical cosmeceuticals. Dermatol Ther 2007:20:330-42

31. Kuttan R, Sudheeran PC, Josph CD: Turmeric and curcumin as topical agents in cancer therapy. Tumori 1987;73:29-31.

32. Parsad D, Pandhi $R$, Juneja $A$ : Effectiveness of oral Ginkgo biloba in treating limited, slowly spreading vitiligo. Clin Exp Dermatol 2003;28:285-7.

33. Whitton ME, Ashcroft DM, González U: Therapeutic interventions for vitiligo. J Am Acad Dermatol 2008:59:713-7. 
34. Chuarienthong P, Lourith $N$, Leelapornpisid P: Clinical efficacy comparison of anti-wrinkle cosmetics containing herbal flavonoids. Int J Cosmet Sci 2010;32:99-106.

35. Kim HS, Kim DH, Kim BK, Yoon SK, Kim MH, et al: Effects of topically applied Korean red ginseng and its genuine constituents on atopic dermatitis-like skin lesions in NC/Nga mice. Int Immunopharmacol 2011;11:280-5.

36. $\mathrm{C}$ ho $\mathrm{S}$, Won $\mathrm{CH}$, Lee $\mathrm{DH}$, Lee $\mathrm{MJ}$, Lee $\mathrm{S}$, et al: Red ginseng root extract aincreases type I procollagen synthesis in human skin: a randomized, double-blind, placebo-controlled study. J Med Food 2009;12:1252-9.

37. Singh RP, Agarwal R: Cosmeceuticals and silibinin. Clin Dermatol 2009;27:479-84.

38. Katiyar SK, Mantena SK, Meeran SM: Silymarin protects epidermal keratinocytes from ultraviolet radiation-induced apoptosis and DNA damage by nucleotide excision repair mechanism. PloS One 2011;6:21410.

39. Dhanalakshmi S, Mallikarjuna GU, Singh RP, Agarwal R: Silibinin prevents ultraviolet radiation-caused skin damages in SKH-1 hairless mice via a decrease in thymine dimer positive cells and an up-regulation of p53-p21/ Cip1 in epidermis. Carcinogenesis 2004;25:1459-65.

40. Levin J, Momin SB: How much do we really know about our favorite cosmeceutical ingredients? J Clin Aesthet Dermatol 2010;3:22-41.

41. Südel KM, Venzke K, Mielke H, Breitenbach U, Mundt C, et al : Novel aspects of intrinsic and extrinsic aging of human skin: beneficial effects of soy extract. Photochem Photobiol 2005;81:581-7.

42. Leu S, Havey J, White LE, et al: Accelerated resolution of laser-induced bruising with topical $20 \%$ arnica: a rater-blinded randomized controlled trial. Br J Dermatol 2010;163:557-63.

43. Janjua R, Munoz C, Gorell E, et al: A two-year, double-blind, randomized placebo-controlled trial of oral green tea polyphenols on the long-term clinical and histologic appearance of photoaging skin. Dermatol Surg 2009;35:1057-65
44. Morse PF, Horrobin DF, Manku MS, et al: Meta-analysis of placebo-controlled studies of the efficacy of Epogam in the treatment of atopic eczema. Relationship between plasma essential fatty acid changes and clinical response. Br J Dermatol 1989;121:75-90.

45. Wright S, Burton JL: Oral evening-primrose-seed oil improves atopic eczema. Lancet 1982;2:1120-2.

46. Belch JJ, Shaw B, O'Dowd A, et al: Evening primrose oil (Efamol) in the treatment of Raynaud's phenomenon: a double blind study. Thromb Haemost 1985;54:490-4.

47. Gaby AR: Natural remedies for scleroderma. Altern Med Rev 2006;11:188-95.

48. Dove D, Johnson P: Oral evening primrose oil: its effect on length of pregnancy and selected intrapartum outcomes in low-risk nulliparous women. J Nurse Midwifery 1999;44:320-4.

49. Cronin $\mathrm{H}$, Draelos ZD: Top 10 botanical ingredients in 2010 anti-aging creams. J Cosmet Dermatol 2010;9:218-25.

50. Reuter J, Wölfle U, Weckesser S, Schempp C: Which plant for which skin disease? Part 1: Atopic dermatitis, psoriasis, acne, condyloma and herpes simplex. J Dtsch Ges 2010;8:788-96.

51. Da Nagao Y, Sata M, Suzuki H, Tanikawa K, Itoh K, Kameyama T: Effectiveness of glycyrrhizin for oral lichen planus in patients with chronic HCV infection. J Gastroenterol 1996;31:691-5.

52. Strandberg TE, Jarvenpaa AL, Vanhanen H, McKeigue PM: Birth outcome in relation to licorice consumption during pregnancy. Am J Epidemiol 2001;153:1085-8.

53. Farnsworth NR, Bingel AS, Cordell GA, Crane FA, Fong HH: Potential value of plants as sources of new antifertility agents I. J Pharm Sci 1975:64:535-98.

54. Calabrese C, Preston P: Report of the results of a double-blind, randomized, single-dose trial of a topical $2 \%$ escin gel versus placebo in the acute treatment of experimentally-induced hematoma in volunteers. Plant Med 1993;59:394-7.

55. Klebanoff MA, Levine RJ, DerSimonian R, Clemens JD, Wilkins DG: Maternal serum paraxanthine, a caffeine metabolite, and the risk of spontaneous abortion. N Engl J Med 1999;341:1639-44. 